\title{
Environmental pollutants leading to carcinogenesis: process of natural selection of human cells due to chronic inflammation and sustained stress environment
}

\author{
H. N. Venkatesh ${ }^{1}$ M. Jeru Manoj ${ }^{1}$ - D. Ghosh $^{1}$ - G. K. Chetan ${ }^{1}$
}

Received: 9 July 2014/Revised: 3 January 2015 / Accepted: 9 March 2015/Published online: 9 April 2015

(C) Islamic Azad University (IAU) 2015

\begin{abstract}
Epidemiological studies have shown that $70-90 \%$ of all cancers are caused due to the chemicals present in environment. Exogenous exposure to carcinogens and their interaction with genetic sequences and endogenous factors, like exposures to products of metabolism which lead to acute stress, disruption of hormones and inflammation of tissues, are triggering factors. Due to relatively small risk of cancer following immediate exposure, the precise quantification of the burden of human cancer attributed to environmental exposure remains ambiguous, thereby leading to an assumption that a causal relationship is relatively large. Research suggests that 90-95\% of all cancers have their roots in the environmental effects on the DNA leading to genetic defects, whereas only $5-10 \%$ can be attributed to inherited genetic defects. The hypothesis of the present review is that response of the cells to the environmental stimulants could be an evolutionary process of adaptation of the DNA. Carcinogenesis is considered as a process of adaptation of mammalian cells to sustained stress environment (SSE) by means of epigenetic alteration (EA) of the genome, mutations which arise due to EA and finally, natural selection of originated mutant cells evading apoptosis. Process of adaptation to SSE involves the emergence of senescent epigenetically reprogrammed cells with specific cancerrelated EA in the genome.
\end{abstract}

G. K. Chetan

drchetangk@gmail.com

1 Department of Human Genetics, National Institute of Mental Health and Neurosciences (NIMHANS), Bangalore 560029, India
Keywords DNA damage - Environmental risk factors · Epigenetic alterations - Genetic risk factors - Adaptive cell environment

\section{Introduction}

Cancer cells are formed from normal cells due to a modification/mutation of DNA and/or RNA. Cancer risk is enhanced in people of old age and those with genetic predisposition to mutations. Research estimates that as many as 2 in 3 cases of cancer $(67 \%)$ are linked to some type of environmental factor (NCI and NIEHS 2003). These environmental factors collectively conspire with internal genetic mutations to destabilize normal checks and balances on growth and maturation, which in turn lead to cancer (NCI and NIEHS 2003). Lifestyle activities like smoking and excessive alcohol consumption also act as risk factors (Anand et al. 2008). The causal risk factor for cancer-related deaths include $25-30 \%$ due to tobacco, 30-35\% due to diet, $15-20 \%$ due to infections and the remaining due to other factors like hormones, stress, physical activity, environmental pollutants, and radiation (Anand et al. 2008). Global cancer statistics suggest the most frequently diagnosed cancers leading to deaths to be lung, colorectal, stomach and esophagus without considering gender-associated cancers, like breast and prostrate (Jemal et al. 2011). Lung cancer, being the most common cause of cancer-related death, is attributable mainly to smoking habit and exposure to air pollutants (López-Cima et al. 2013). This statistics prove the direct co-relation of causal environmental risk factors and cancer incidence.

Cancer risk appears to follow combinations of multicellularity, cell replacement, genetic and epigenetic 
changes that occur over longtime (Crespi and Summers 2005). Therefore, identification and validation of chemicals present in environment will have significant impact on better understanding and management of cancer (Jamal et al. 2012).

\section{Cellular damage by environmental factors}

Humans exist in a contaminant-rich environment; an individual's internal genetic makeup persistently interacts with the environmental pollutants. External factors such as diet, sunshine, viruses, bacteria, fungi, parasites, electromagnetic radiation, microwaves, X-rays, gamma rays, ultraviolet rays, cosmic, ultrasound and nuclear radiation lead to some form of cellular damage (Boffetta and Nyberg 2003). Exogenous factors and certain lifestyle practices trigger certain endogenous processes such as inflammation. All these factors lead to cellular oxidative stress, which causes DNA damage and produces free radicals, creating an unhealthy cell environment leading to tissue inflammation (Uttara et al. 2009), which may lead to cancer by continuous exposure to carcinogens.

DNA damage, due to environmental factors and normal metabolic processes, occurs at a high rate of 1000-1,000,000 molecular lesions per cell per day. While this constitutes only $0.000165 \%$ of the human genome's $\sim 6$ billion bases ( 3 billion base pairs), unrepaired lesions in critical genes (such as tumor suppressor genes, DNA repair genes) can impede a cell's ability to carry out its function and thus appreciably increase the likelihood of cancer formation (Lodish et al. 2004). Hence, cancer cells are very similar to cells of the organs/tissue from which they originated, but are rapidly dividing and their number of divisions is not limited by telomeres on DNA, leading to failure in regulating tissue growth (Colotta et al. 2009). Activation/inactivation of certain genes propagates DNA damage, leading to cellular damage, which enhances cancer development (Green and Lin 2012). The need is to establish risk of substances in polluted environment which has cascade effects like interfering in pathways that maintain homeostasis and integrity of cells.

\section{Carcinogenesis}

\section{Process of carcinogenesis}

Carcinogenesis is a multi-step process: Cancer promoters such as wounding or inflammation promote growth by increasing local blood flow (Gillies et al. 2012). Following promotion step, cancer growth is eventually slowed due to substrate limitation, caused by the anatomic constraints imposed by intra-ductal growth, triggering a cascade of events like regional hypoxia, upregulation of glycolysis, microenvironmental acidosis and cellular adaptation to acid-induced toxicity (Gatenby and Gillies 2004). This leads to cancer initiation which results from mutations that weaken local tissue growth constraints, thereby conferring a selective advantage (Vincent and Gatenby 2008).

Genes which regulate cell growth and differentiation are altered, caused by DNA sequence mutations, gain of function of proto-oncogenes, loss of function of tumor suppressor genes and as well as by epigenetic alterations (EA). Epigenetic deficiencies in expression of DNA repair genes likely cause an increased frequency of mutations (Bernstein et al. 2013). The dynamics of genetic and epigenetic gene silencing in response to environmental stimulants vary. Somatic gene mutation leads to a block in the production of functional protein from the mutant allele, and if it confers a selective advantage to the cell, the cells expand clonally to give rise to cancer, in which all cells lack the capacity to produce a functional protein (Podlaha et al. 2012), whereas epigenetically mediated gene silencing occurs gradually, beginning with a subtle decrease in transcription, promoting decrease in protection of the $\mathrm{CpG}$ island from the spread of flanking heterochromatin and methylation into the island. This loss results in a gradual increase in individual $\mathrm{CpG}$ sites, thus accounting for variation between copies of the same gene in different cells (Bartsch and Hietanen 1996).

These sequences of development are critical for evolution of the malignant phenotype, as the adaptive advantage of a cell confers the ability to destroy other populations, a necessary final step in carcinogenesis. This differs from the conventional assumption that promotion and initiation act by increasing cellular proliferation (Vincent and Gatenby 2008). The process of carcinogenesis, thus, is not only due to cell proliferation, but rather due to a change in the genetic configuration of the normal tissue's adaptive capacity leading to mutant cell populations' growth and evolution, in response to the environmental stimulants (Podlaha et al. 2012). The focus of the review is to list the roles of carcinogens present in daily usage substances and relate the biological changes caused by them to a natural adaptive mechanism.

\section{Role of environmental carcinogens in carcinogenesis}

Carcinogens present in environmental pollutants are basically classified into genotoxic and non-genotoxic (Yamasaki et al. 1992). Genotoxic-chemicals-induced carcinogenesis involves direct chemical interaction with DNA (carcinogens or activated pro-carcinogens). DNA contains nucleophilic bases and, as such, is strongly attracted to electrophilic compounds. Carcinogens such as 
epoxides, nitrogen mustards, nitrosoureas and nitrosamines and, additionally, pro-carcinogens such as polycyclic aromatic hydrocarbons, aromatic amines, mycotoxins (including aflatoxin) and, again, nitrosamines, may also act by this mechanism (Belitsky and Yakubovskaya 2008). Continuous exposure to carcinogens creates a huge diversity of DNA adducts like ethenobases, oxidized bases, alkylated phosphotriesters and cross-linking of DNA (Povey 2000). The replication of damaged DNA before cell division can lead to mismatch base incorporation. Daughter cells that inherit these wrong mismatch bases carry mutations from the parental DNA sequence (Peltomäki 2001). Indirect chemical interference with DNA occurs with antimetabolites such as purine and pyrimidine analogues, which inhibit the synthesis of purine or pyrimidine bases and therefore inhibit the synthesis of DNA. Intercalating agents interpose between the strands within the grove of DNA, thereby inhibiting its replication/transcription (Belitsky and Yakubovskaya 2008), leading to accumulation of DNA adducts. DNA exogenous damage include UV-B light, which causes cross-linking between adjacent cytosine and thymine bases creating pyrimidine dimers, called direct DNA damage, and UV-A light, which creates mostly free radicals (Berg et al. 2002). Low-level ionizing radiation may induce irrepairable DNA damage (leading to replication and transcriptional errors needed for neoplasia or may trigger viral interactions) leading to premature aging and cancer (Berg et al. 2002). Thermal disruption at elevated temperature increases the rate of depurination and single-strand breaks. The rate of depurination (300 purine residues per genome per generation) is too high to be repaired by normal repair machinery (De Bont and van Larebeke 2004). These damages to DNA lead to inactivation of DNA repair and changes in gene expression of important genes leading to cancer-related EA in the genome.

This reprogramming of DNA may be induced only by continuous exposure to environmental pollutants by various mechanisms other than the ones mentioned above, which include interference with enzyme control or enzyme repair mechanisms, damage to the histone which may allow unregulated or improperly controlled DNA replication, immunosuppressant drugs and toxicants that depress the immune system like viral infections that inhibit normal DNA function and decreases natural killer cells (Belitsky and Yakubovskaya 2008). Molecular biomarker studies have suggested that effects of contaminant types and concentrations depend on individuals' susceptibility to these carcinogens; genetic polymorphisms may contribute to this variability (Wogan et al. 2004). The list of the different subclasses of environmental carcinogens and the biological damage they cause, leading to cancers, is given in Table 1.

\section{Sustained stress environment}

During carcinogenic transformations, a sustained stress environment (SSE) - cellular environment consisting of persistent production of proliferative and stress-related survival signals-is created, which may lead to cells generating mutations by themselves as a result of mutator response, an error-prone cell cycle progression with participation of error-prone polymerases and aberrant mitosis (Karpinets and Foy 2005). This process gives rise to arrested cells because of DNA damage or replicative senescence. Stress-related survival signals induce a combination of intracellular proliferative signals and blockade of apoptosis in the arrested cells, thereby disturbing cell cycle arrest and activation of error-prone cell cycle progression (Klein 2013). These changes, in combination with EA, ensure the high adaptive potential modifications in the genome of cancer cells, but mutations in the error-prone replications of epigenetically reprogrammed cells are not random. The process of adaptation to SSE involves the emergence of senescent epigenetically reprogrammed (ER) cells with specific tumor-related EA in the genome (Karpinets and Foy 2005). Epigenetic reprogramming includes (i) hypermethylation of tumor suppressor genes involved in the onset of cell cycle arrest, apoptosis and DNA repair; (ii) hypomethylation of proto-oncogenes associated with persistent proliferative activity; and (iii) the global demethylation of the genome and activation of DNA repeats. These epigenetic changes in the proliferating cells associate with their replicative senescence and allow the reprogrammed senescent cells to overcome the cell cycle arrest and to activate error-prone replications leading to trigger of Ras/ Raf/MEK/ERK pathway which is responsible for cellular senescence in several cell types. Continuing replication of some cells in SSE leads to their senescence in a way that cannot be accomplished by cell cycle arrest, because, in addition to the replicative senescence, these cells have epigenetically silenced genes involved in cell cycle control. p53 and p16 are important cell cycle inhibitors which undergo epigenetic reprogramming in the form of hypermethylation and transcriptional silencing due to SSE. Their activity is indispensable to accomplish senescence by cell cycle arrest; hence, inactivation of these genes prevents cell cycle arrest and results in carcinogenic transformation (Karpinets and Foy 2005).

Continuous DNA damage leads to increased rate of mutations which are crucial components of carcinogenic potential acquired after epigenetic reprogramming of the cells in SSE, allowing the cells to easily overcome subsequent stresses imposed by cancer progression (Karpinets and Foy 2005). Epigenetically reprogrammed transformed cells are faced with a shortage of oxygen or nutrients 


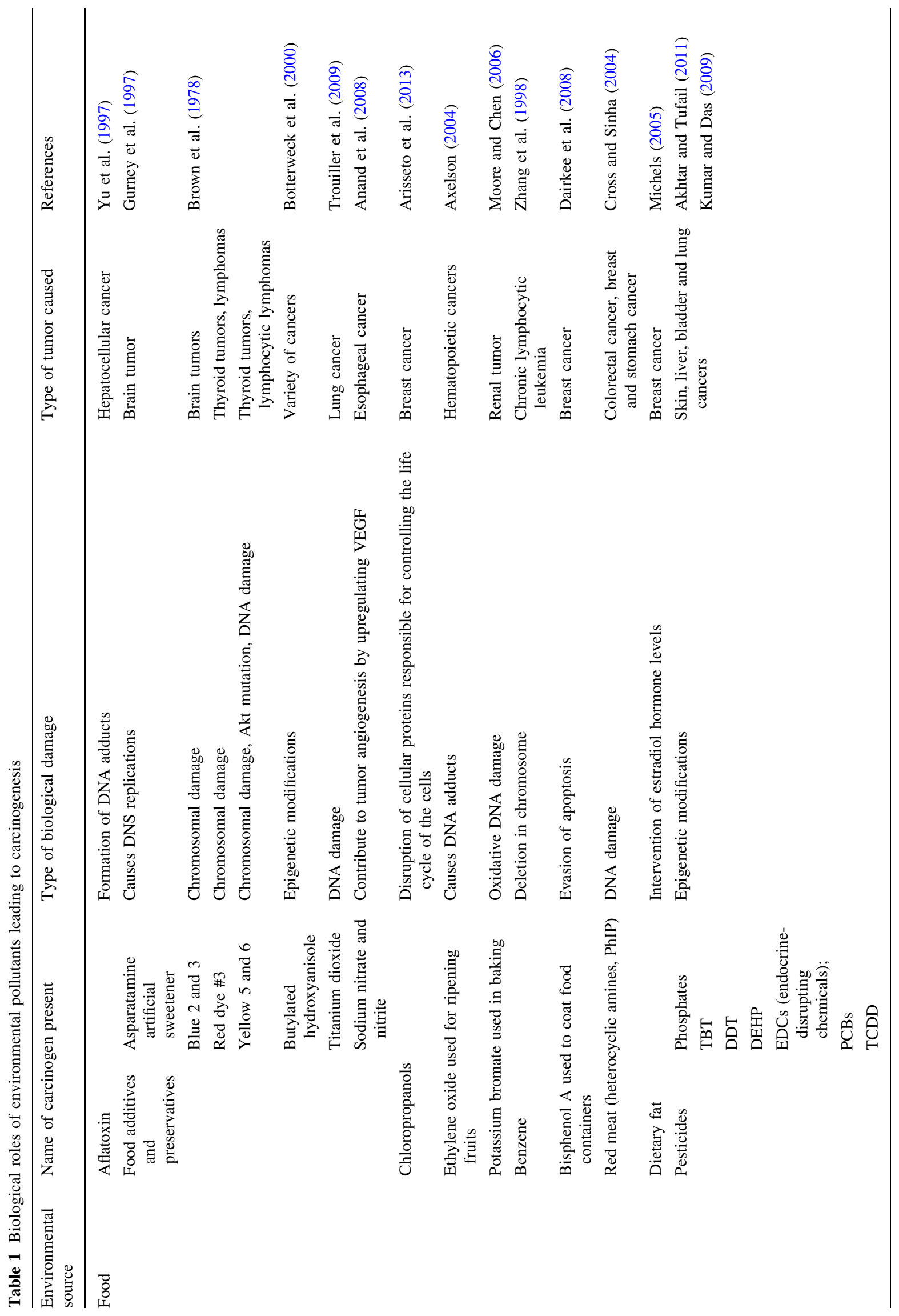




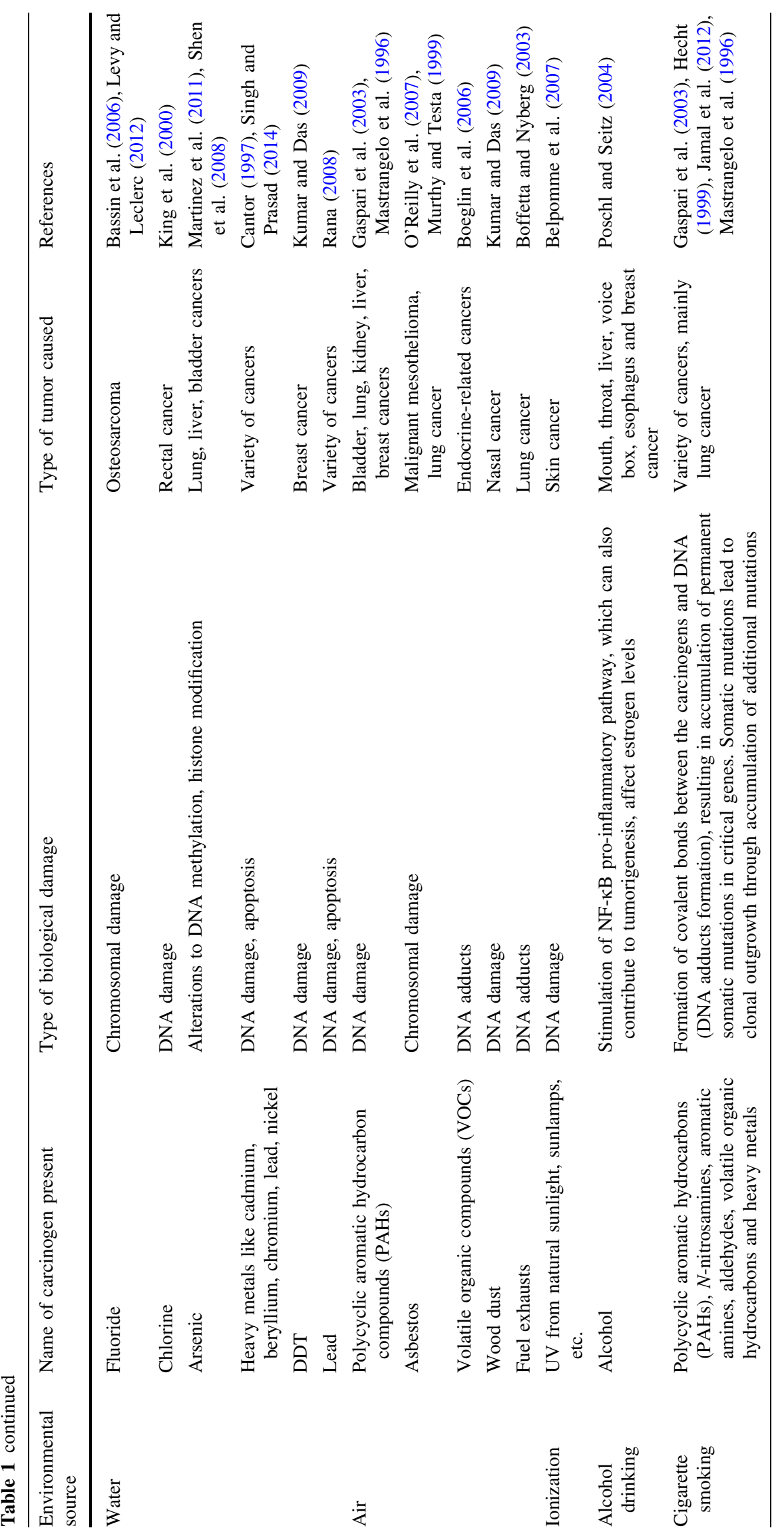




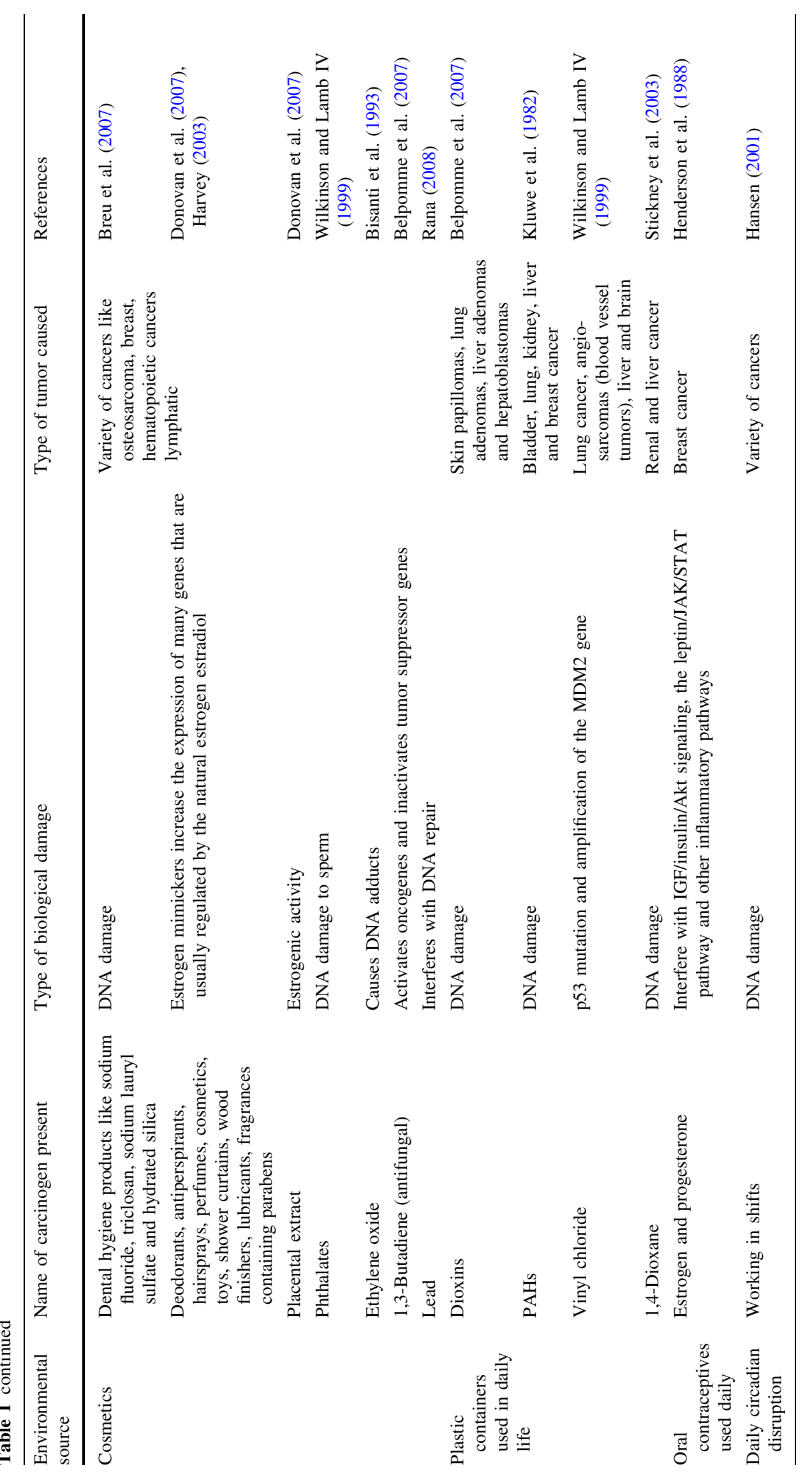


induced by overcrowding and can easily express those genes that increase their mobility and allow them to migrate and proliferate in new environments (Bernstein et al. 2013). In this way, cancer cells acquire sequential specialized adaptations that confer metastatic capabilities. It includes the expression of metalloproteinases, angiogenesis, lymphangiogenesis and adhesion, which are of beneficial nature to the natural selection and progression of cancer cells (Klein 2013).

\section{Inflammatory response to environmental stimulants, a triggering factor}

Inflammation is one of the natural immune responses of the body, a complex biological process which has protective functions against environmental infections and carcinogenic chemicals (Jaiswal et al. 2000). Diet and lifestyle play a role in inflammation contributing to the body becoming overly acidic. Cells function healthiest in a slightly alkaline $\mathrm{pH}$ 7.34; hence, those chemicals are not recognized as foods at an acidic $\mathrm{pH}$, directly contributing to most illnesses including cancer (Zavros et al. 2005), e.g., stomach cancer. Medical experts agree that $\mathrm{pH}$ balance is a key factor in controlling inflammation. Even though many DNA alterations occur for cancer formation, inflammation is very important aspect of cancer in order to maintain integrity and homeostasis in SSE cells.

\section{Role of cytokines}

Inflammation leads to production of cytokines which activate proliferative stress-related survival signals in the cells. Proliferative signaling activates genetic pathways involved in cellular replication and suppresses the activation of cell cycle arrest and apoptosis (Jaiswal et al. 2000). Inflammatory cytokines, can epigenetically activate or inactivate certain genes. It causes DNA damage, triggers Myc/NF- $\kappa \mathrm{B}$ pathway and anti-apoptosis pathways like Bcl-2/IAP-1 which causes tumor formation (Ranson et al. 2003).

\section{Role of IL-15}

During chronic inflammation, IL-15 is present in high amounts for prolonged periods; IL-15 binds to receptors on the surface of normal large granular lymphocytes and activates cancer-causing protein called Myc (Anand et al. 2008). The high Myc levels bring changes that cause chromosome instability, additional gene mutations and also activate a process called DNA methylation, which turns off a variety of tumor suppresser genes (Mishra et al. 2012). These tend to stimulate the development, survival and proliferation of natural killer cells, i.e., one of the immune cells which help in destruction of cancer and virus-infected cells (Ranson et al. 2003).

\section{Role of $N F-\kappa B$}

Chronic inflammation precedes carcinogenesis. Most carcinogens and other risk factors for cancer have been shown to activate nuclear transcription factor (NF- $\mathrm{kB})$, a major mediator of inflammation (Fan et al. 2000). The mechanism of how it is mediated includes a cascade of steps: Inflammatory markers such as cytokines (TNF, IL-1, IL-6 and chemokines), enzymes (COX-2, 5-LOX and matrix metalloproteinase-9 [MMP-9]) and adhesion molecules (such as intercellular adhesion molecule-1, endothelium leukocyte adhesion molecule-1 and vascular cell adhesion molecule-1) are activated and regulated by NF- $\kappa \mathrm{B}$ (Fan et al. 2000).

$\mathrm{NF}-\kappa \mathrm{B}$ has also been shown to control the expression of other gene products linked with carcinogenesis such as cancer cell survival or anti-apoptosis (Bcl-2, Bcl-xL, IAP1, IAP-2, XIAP, survivin, cFLIP and TRAF-1), proliferation (such as c-Myc and cyclin D1), invasion (MMP-9) and angiogenesis (vascular endothelial growth factor)(Fan et al. 2000). Polymorphisms of TNF, IL-1, IL-6 and D1 genes encountered in various cancers are all regulated by NF- $\mathrm{KB}$ (Ranson et al. 2003). Most chemotherapeutic agents and $\gamma$-radiation, used for the treatment of cancers, also lead to activation of NF- $\mathrm{KB}$, which has been linked with chemoresistance and radioresistance. Mutations in genes encoding for inhibitors of NF- $\mathrm{KB}$ have also been reported (Wallace et al. 2010). Suppression of NF-kB inhibits the proliferation of cancers by induction of apoptosis, inhibition of invasion and suppression of angiogenesis (Wallace et al. 2010). All chemopreventive agents have been shown to suppress NF- $\kappa B$ activation (Bharti and Aggarwal 2002). An additional mechanism involved in cancer-related inflammation (CRI) is induction of genetic instability by inflammatory mediators, leading to accumulation of random genetic alterations in cancer cells (Anand et al. 2008; Colotta et al. 2009).

\section{Cellular evolution of cancer cells, a process of natural selection}

Emerging research indicates that reaction of cell to environmental stimulants may be an evolutionary process of adaptation for survival; therefore immune system cannot detect cancer cells as they are derivatives of normal cells. Population biology and evolutionary theory have demonstrated how selective agents drive the somatic evolution of cancer in promoting carcinogenesis. Most cancers exhibit a 
strong environmental component owing to the effects of carcinogens and physiological factors (Anand et al. 2008). Rapid changes in ecological traits, such as diet and lifestyle might, therefore, drive increased cancer risk, as a result of maladaptive mismatches between ancestral and current environments (Crespi and Summers 2005). This evolutionary potential of cells allows them to adapt to specific microenvironmental selection forces. Normal epithelial cells have a novel adaptive landscape that permits coexistence of normal cellular population and also allows invasion by mutant phenotypes; cancer evolution is mediated by cell-cell and cell-extracellular matrix interactions and adaptations in response to perturbations in microenvironment (Vincent and Gatenby 2008).

Cancers often develop in low-oxygen tissue environments before becoming vascularized, unfavorable for effective immune function (Crespi and Summers 2005). Somatic selection of cancer is driven by differential replication of cells that differ phenotypically as a result of genetic mutation and epigenetic alteration (Crespi and Summers 2005). This somatic evolution leads to adaptations such as increased proliferation, angiogenesis and invasion (Podlaha et al. 2012). EA in the genome imposed by proliferative and survival signaling in SSE drives the cancer development (Gatenby and Gillies 2004). EA primes the cells for error-prone replications and provides an epigenetic tag in the genome for beneficial mutations, an adaptive strategy wherein the somatic cells of mammals respond to SSE (Pepper et al. 2009). This plays an important role in the development of malignances and also for creating varied susceptibility.
Research using the mathematical model for understanding tumorigenesis has also demonstrated the following: Healthy tissue of multi-cellular organisms possesses an adaptive cell environment that allows coexistence of nonevolving normal cell populations. However, it also permits invasion by fitter phenotypes. Thus, the potential for carcinogenesis is a natural 'penalty' incurred due to tissue permitting multi-cellular function (Spencer et al. 2006).

Natural selection operates on the phenotypic variability generated by the accumulation of genetic, genomic and epigenetic alterations, like point mutations, deletions, gene fusions, gene amplifications and chromosomal re-arrangements (Podlaha et al. 2012). The natural selection of the cells is accelerated by their continuing proliferation in stressful environment, thus favoring the survival of mutant cells leading to the emergence of transformed cells. This process, being a natural selection, is the reason why cancer cells are not very often detected by the immune system (Maley and Reid 2005).

Cancer prevention by pharmacological interventions reverses the process by inhibition of mutagenesis, oxidative stress and inflammation by increasing the expression of electrophile-detoxifying enzymes and antioxidant proteins (Kwak and Kensler 2013). Anticancer drugs including novel targeted therapies stimulate autophagy, an evolutionarily conserved catabolic process which acts as cellular housekeeper to eliminate damaged organelles and recycle macromolecules, particularly during malignant transformation and carcinogenesis, by inhibiting the $\mathrm{PI} 3 \mathrm{~K} / \mathrm{Akt} / \mathrm{mTOR}$ axis or altering genetic/epigenetic phenotype of cancer cells (Sui et al. 2013). Taxol, most
Fig. 1 'Carcinogenesis due to continuous exposure to environmental pollutants', is a natural adaptive mechanism of the cell

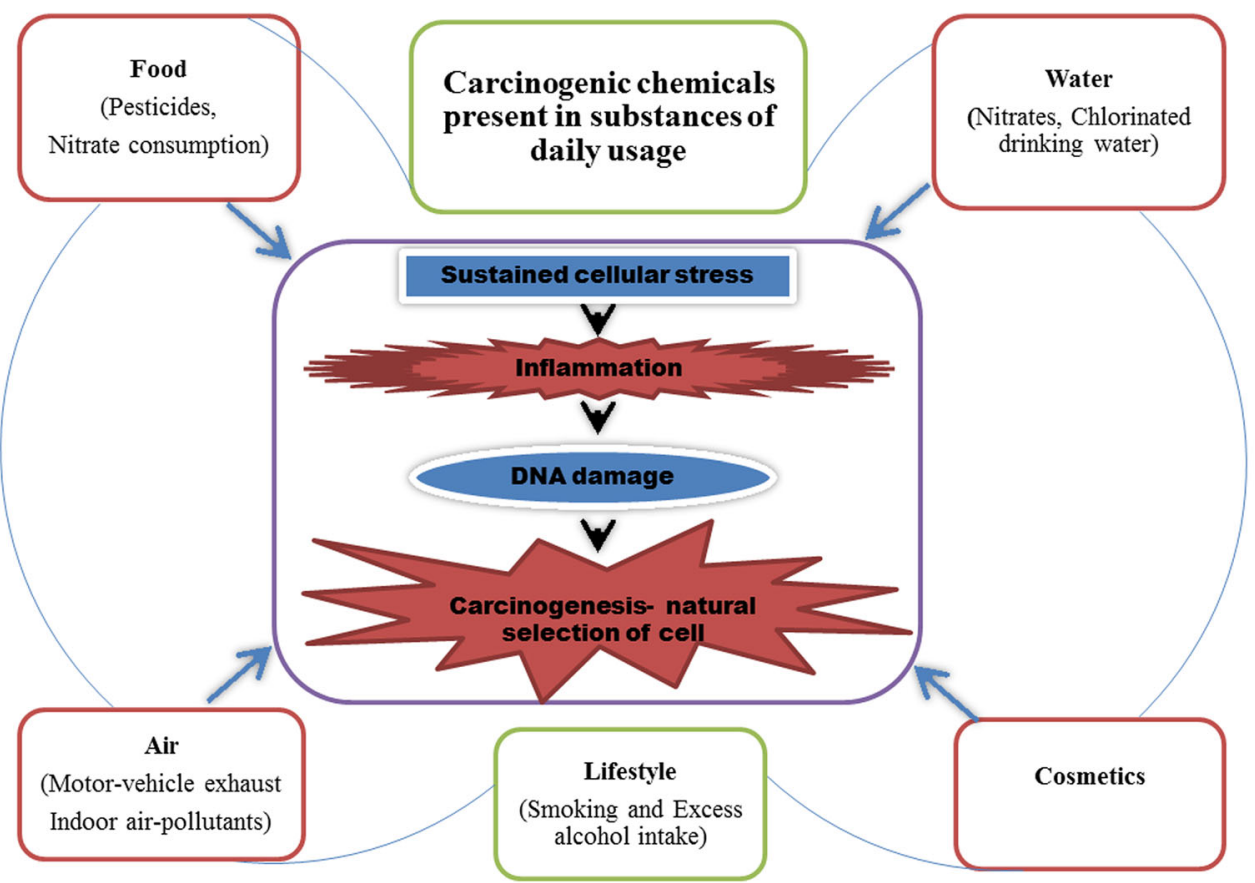


commonly used intervention, acts by stabilizing microtubules and thereby arresting cycling cells in the G2/M phase (Liu et al. 2012). Oleanane triterpenoids have a strong inhibitory effect on an inflammatory response leading to chemoprevention against chemical carcinogenesis (Kwak and Kensler 2013).

\section{Conclusion}

This review is based on the current knowledge of the role of environmental factors in carcinogenesis. Environment pollutants present in daily routine needs are consistently associated with development of cancer. They are the key mediators for various molecular changes in the cells, including DNA damage, mutation, gene silencing, epigenetic changes. The chance that an individual may develop cancer due to continuous exposure to carcinogens depends upon a lot of factors which include addictiveness/response to rapid change in environment, coevolution of pathogens, inflammation and genetic susceptibility. It also depends on several interacting factors like the longevity, frequency of exposure to particular carcinogens and associated reactions with other environmental agents like age, gender, health, diet, hormonal imbalances, lifestyle practices like tobacco and betel nut chewing, cigarette smoking, alcohol consumption. Individuals differ in their susceptibility to these carcinogens, and genetic polymorphisms may contribute to this variability (Wogan et al. 2004).

Gene alterations contribute to individual differences in susceptibility to cancer (Cancer and the Environment 2003). Random inherited mutations in a particular environment cause some of the variations. This difference has a chance of survival due to adaptive evolution, and so individuals' cells will have better potential to survive according to natural selection theory for development of cancer. Pharmacological alterations to reverse the evolutionary process adaptive to cancer cell growth will be of great importance for the treatment after understanding the environmental mutagenesis.

We propose the hypothesis based on evolutionary concept considering the underlying mechanisms that environmental carcinogens mediate carcinogenesis in a cell, through a process of natural selection adapted in the body to combat the external changes, a gradual process of adaptation, due to uncommon gene alterations at critical regions of the genome (Fig. 1). Identification of significant chemical substances present in environment and modifying environmental factors in the adaptive landscape could possibly have impact on prevention of cancer. We are now entering a new era of cancer research in which patients may be stratified for appropriate therapy on the basis of the
DNA damage response status of their tumor, rather than on the tissue of origin (Curtin 2012).

Implication and evaluation of our hypothesis include the following: Though environmental chemicals mediate inflammatory response leading to carcinogenesis, genetic variations within the population are responsible for susceptibility to cancer. This random inherent mutations, occurring in a particular environment due to continuous exposure and genetic susceptibility is a process of natural selection.

\section{Future significance}

Modifying environmental factors in the adaptive landscape could possibly minimize cancer growth. For example, if the landscape located at the cancer strategy value could be changed from a positive to a negative slope, evolution would tend to move the cancer cell strategy back toward aerobic metabolism (Vincent and Gatenby 2008). This might be accomplished by modifying the microenvironment of the cancer by altering the $\mathrm{pH}$, which could alter the selection pressures in the adaptive landscape. Similarly, induction of brief systemic acidosis (by vigorous exercise, for example) might sufficiently alter the environment in premalignant lesions to slow or revert the evolutionary process (Mierke 2013). Pharmacological alterations in cellular adaptations to the predicted sequence of environmental changes may block evolution of the malignant phenotype, e.g., drugs that block the $\mathrm{Na}+\mathrm{H}+$ anti-port may reduce the ability of cells to adapt to acidic environments and halt the evolutionary process (Vincent and Gatenby 2008). The future of pharmacology intervention will be toward targeting the EA; this being a reversible process will reverse the SSE created during carcinogenesis. Pharmacological inhibition of individual components to reprogram the EA may result in DNA demethylation and complex disintegration leading to reversal through resetting multiple processes (Tsai and Baylin 2011). Pharmacogenetics and pharmacogenomics are emerging fields that aim to overcome the failure in routine pharmacological intervention occurring due to individual genetic variability and drug metabolic susceptibility. To conclude, there also exists a natural selection mechanism within the cell which could reverse the process of carcinogenesis, through any of natural processes like autophagy. Profounding knowledge about these mechanisms, learning the value of good lifestyle practices like exercising, eating healthy and strengthening mindset on a daily basis might enhance the cell to turn into cancer-fighting machine.

Acknowledgments We are thankful to the Department of Human Genetics, NIMHANS, Bangalore, and the Institute for providing the encouragement and research facilities. Jeru Manoj M. is thankful to 
UGC for awarding MANF fellowship, and Debarati Ghosh is thankful to DST-SERB for giving the opportunity to work in the project. Finally, the anonymous reviewers are thanked for their valuable comments which enhanced the previous submission.

\section{References}

Akhtar N, Tufail M (2011) Cancer risk in Pakistan due to natural environmental pollutants. Int J Environ Res 5(1):159-166

Anand P, Kunnumakkara AB, Sundaram C, Harikumar KB, Tharakan ST, Lai OS, Sung B, Aggarwal BB (2008) Cancer is a preventable disease that requires major lifestyle changes. Pharm Res 25(9):2097-2116. doi:10.1007/s11095-008-9661-9

Arisseto AP, Vicente E, Furlani RPZ, Toledo MCDF (2013) Estimate of dietary intake of chloropropanols (3-MCPD and 1, 3-DCP) and health risk assessment. Ciência E Tecnologia de Alimentos 33(1):125-133. Retrieved from http://www.scielo.br/pdf/cta/ v33s1/v33s1a19.pdf

Axelson O (2004) Ethylene oxide and cancer. Occup Environ Med 61:1. Retrieved from http://www.pubmedcentral.nih.gov/ articlerender.fcgi?artid $=3138010 \&$ tool=pmcentre $\&$ rendertype $=$ abstract

Bartsch H, Hietanen E (1996) The role of individual susceptibility in cancer burden related to environmental exposure. Environ Health Perspect 104(3):569-577. Retrieved from http://www. pubmedcentral.nih.gov/articlerender.fcgi?artid $=1469659 \&$ tool $=$ pmcentrez\&rendertype $=$ abstract

Bassin EB, Wypij D, Davis RB, Mittleman MA (2006) Age-specific fluoride exposure in drinking water and osteosarcoma (United States). Cancer Causes Control 17(4):421-428. doi:10.1007/ s10552-005-0500-6

Belitsky GA, Yakubovskaya MG (2008) Genetic polymorphism and variability of chemical carcinogenesis. Biochemistry (Moscow) 73(5):543-554

Belpomme D, Irigaray P, Hardell L, Clapp R, Montagnier L, Epstein S, Sasco AJ (2007) The multitude and diversity of environmental carcinogens. Environ Res 105(3):414-429. doi:10.1016/j.envres. 2007.07.002

Berg JM, Tymoczko JL, Stryer L (2002). Section 27.6, mutations involve changes in the base sequence of DNA. In: Biochemistry. 5th edn. Retrieved from http://www.ncbi.nlm.nih.gov/books/ NBK22525/

Bernstein C, Nfonsam V, Prasad AR, Bernstein H (2013) Epigenetic field defects in progression to cancer. World J Gastrointest Oncol 5(3):43-49. doi:10.4251/wjgo.v5.i3.43

Bharti AC, Aggarwal BB (2002) Chemopreventive agents induce suppression of nuclear factor-kappaB leading to chemosensitization. Ann N Y Acad Sci 973:392-395. Retrieved from http:// www.ncbi.nlm.nih.gov/pubmed/12485899

Bisanti L, Maggini M, Raschetti R, Alegiani SS, Ippolito FM, Caffari B, Segnan N, Ponti A (1993) Cancer mortality in ethylene oxide workers. Br J Ind Med 50(4):317-324. Retrieved from http:// www.pubmedcentral.nih.gov/articlerender.fcgi?artid= $1061288 \&$ tool $=$ pmcentrez\&rendertype $=$ abstract

Boeglin ML, Wessels D, Henshel D (2006) An investigation of the relationship between air emissions of volatile organic compounds and the incidence of cancer in Indiana counties. Environ Res 100(2):242-254. doi:10.1016/j.envres.2005.04.004

Boffetta P, Nyberg F (2003) Contribution of environmental factors to cancer risk. Br Med Bull 68:71-94. doi:10.1093/bmb/ldg023

Botterweck AAM, Verhagen H, Goldbohm RA, Kleinjans J, van den Brandt PA (2000) Intake of butylated hydroxyanisole and butylated hydroxytoluene and stomach cancer risk: results from analyses in the Netherlands Cohort Study. Food Chem Toxicol
38(7):599-605. Retrieved from http://www.ncbi.nlm.nih.gov/ pubmed/10942321

Breu F, Guggenbichler S, Wollmann J (2007) Food, nutrition, physical activity, and the prevention of cancer: a global perspective. Vasa. American Institute for Cancer Research. Retrieved from http:// medcontent.metapress.com/index/A65RM03P4874243N.pdf

Brown JP, Roehm GW, Brown RJ (1978) Mutagenecity testing of certified food colors and related azo, xanthene and triphenylmethane dyes with the Salmonella/microsome system. Mutat Res 56:249-271

Cancer and the Environment (2003) NIH publication no 03-2039. Retrieved from https://www.niehs.nih.gov/health/materials/ cancer_and_the_environment_508.pdf

Cantor KP (1997) Drinking water and cancer. Cancer Causes Control 8(3):292-308. Retrieved from http://www.ncbi.nlm.nih.gov/ pubmed/23764934

Colotta F, Allavena P, Sica A, Garlanda C, Mantovani A (2009) Cancer-related inflammation, the seventh hallmark of cancer: links to genetic instability. Carcinogenesis 30(7):1073-1081. doi:10.1093/carcin/bgp127

Crespi B, Summers K (2005) Evolutionary biology of cancer. Trends Ecol Evolut 20(10):545-552. doi:10.1016/j.tree.2005.07.007

Cross AJ, Sinha R (2004) Meat-related mutagens/carcinogens in the etiology of colorectal cancer. Environ Mol Mutagen 44(1):44-55. doi:10.1002/em.20030

Curtin NJ (2012) DNA repair dysregulation from cancer driver to therapeutic target. Nat Rev Cancer 12:801-817. doi:10.1038/ nrc3399

Dairkee SH, Seok J, Champion S, Sayeed A, Mindrinos M, Xiao W, Davis RW, Goodson WH (2008) Bisphenol A induces a profile of tumor aggressiveness in high-risk cells from breast cancer patients. Cancer Res 68(7):2076-2080. doi:10.1158/0008-5472. CAN-07-6526

De Bont R, van Larebeke N (2004) Endogenous DNA damage in humans: a review of quantitative data. Mutagenesis 19(3):169-185. doi:10.1093/mutage/geh025

Donovan M, Tiwary CM, Axelrod D, Sasco AJ, Jones L, Hajek R, Sauber E, Kuo J, Davis DL (2007) Personal care products that contain estrogens or xenoestrogens may increase breast cancer risk. Med Hypotheses 68(4):756-766. doi:10.1016/j.mehy.2006. 09.039

Fan Y, Dutta J, Gupta N, Gélinas C (2000) Molecular basis of Oncogenesis-NFkB: from a bird's eye view to a RELevant role in cancer. Madame Curie Bioscience Database [Internet]. Austin (TX): Landes Bioscience. Retrieved from http://www.ncbi.nlm. nih.gov/books/NBK6169/

Gaspari L, Chang S-S, Santella RM, Garte S, Pedotti P, Taioli E (2003) Polycyclic aromatic hydrocarbon-DNA adducts in human sperm as a marker of DNA damage and infertility. Mutat Res 535(2):155-160. doi:10.1016/S1383-5718(02)00297-8

Gatenby RA, Gillies RJ (2004) Why do cancers have high aerobic glycolysis? Nat Rev Cancer 4(11):891-899. doi:10.1038/nrc1478

Gillies RJ, Verduzco D, Gatenby RA (2012) Evolutionary dynamics of carcinogenesis and why targeted therapy does not work. Nat Rev Cancer 12(7):1-7. doi:10.1038/nrc3298

Gurney JG, Pogoda JM, Holly EA, Hecht SS, Preston-Martin S (1997) Aspartame consumption in relation to childhood brain. J Natl Cancer Inst 89(14):14-16

Green LJ, Lin S-Y (2012) DNA damage response and breast cancer: an overview. In: Aft RL (ed) Targeting new pathways and cell death in breast cancer, vol 1. InTech, Rijeka, pp 97-113. doi:10. $5772 / 1744$

Hansen J (2001) Increased breast cancer risk among women who work predominantly at night. Epidemiology 12(1):74-77. Retrieved from http://www.ncbi.nlm.nih.gov/pubmed/11138824 
Harvey PW (2003) Parabens, oestrogenicity, underarm cosmetics and breast cancer: a perspective on a hypothesis. J Appl Toxicol 23(5):285-288. doi:10.1002/jat.946

Hecht SS (1999) DNA adduct formation from tobacco-specific N-nitrosamines. Mutat Res 424(1-2):127-142. Retrieved from http://www.ncbi.nlm.nih.gov/pubmed/10064856

Henderson BE, Ross R, Bernstein L (1988) Estrogens as a cause of human cancer: the Richard and Hinda Rosenthal Foundation award lecture. Cancer Res 48:246-253

Jaiswal M, Larusso NF, Burgart LJ, Gores GJ (2000) Inflammatory cytokines induce DNA damage and inhibit DNA repair in cholangiocarcinoma cells by a nitric oxide-dependent mechanism. Cancer Res 60:184-190

Jamal QMS, Lohani M, Siddiqui MH, Haneef M, Gupta SK, Wadhwa G (2012) Molecular interaction analysis of cigarette smoke carcinogens NNK and NNAL with enzymes involved in DNA repair pathways: an in silico approach. Bioinformation 8(17):795-800. doi:10.6026/97320630008795

Jemal A, Bray F, Ferlay J (2011) Global cancer statistics. Cancer J Clin 61(2):69-90. doi:10.3322/caac.20107.Available

Karpinets TV, Foy BD (2005) Tumorigenesis: the adaptation of mammalian cells to sustained stress environment by epigenetic alterations and succeeding matched mutations. Carcinogenesis 26(8):1323-1334. doi:10.1093/carcin/bgi079

King WD, Marrett LD, Woolcott CG (2000) Case-control study of colon and rectal cancers and chlorination by-products in treated water. Cancer Epidemiol Biomarkers Prev 9:813-818

Klein CA (2013) Selection and adaptation during metastatic cancer progression. Nature 501(7467):365-372. doi:10.1038/nature 12628

Kluwe WM, McConnell EE, Huff JE, Haseman JK, Douglas JF, Hartwell WV (1982) Carcinogenicity testing of phthalate esters and related compounds by the national toxicology program and the national cancer institute. Environ Health Perspect 45:129-133. Retrieved from http://www.pubmedcentral.nih. gov/articlerender.fcgi?artid=1569006\&tool=pmcentrez\&rendertype $=$ abstract

Kumar R, Das BC (2009) Role of environmental factors in Carcinogenesis. Environ We Int J Sci Technol 4:53-69

Kwak M-K, Kensler TW (2013) Targeting NRF2 signaling for cancer chemoprevention. Toxicol Appl Pharmacol 244(1):66-76. doi:10.1016/j.taap.2009.08.028

Levy M, Leclerc B-S (2012) Fluoride in drinking water and osteosarcoma incidence rates in the continental United States among children and adolescents. Cancer Epidemiol 36(2):e83-88. doi:10.1016/j.canep.2011.11.008

Liu XY, Zhang L, Zhang Y, Yang JM (2012) Roles of eEF-2 kinase in cancer. Chin Med J 125(16):2908-2913. doi:10.3760/cma.j.issn. 0366-6999.2012.16.020

Lodish H, Berk A, Matsudaira P, Kaiser CA, Krieger M, Scott MP, Zipursky SL, Darnell J (2004) Molecular biology of the cell, 5th edn. W. H. Freeman, New York

López-Cima MF, García-Pérez J, Pérez-Gómez B, Aragonés N, López-Abente G, Tardón A, Pascual T, Pollán M (2013) Lung cancer risk associated with residential proximity to industrial installations: a spatial analysis. Int $\mathrm{J}$ Environ Sci Technol 10(5):891-902. doi:10.1007/s13762-013-0248-6

Maley CC, Reid BJ (2005) Natural selection in neoplastic progression of Barrett's esophagus. Semin Cancer Biol 15(6):474-483. doi:10.1016/j.semcancer.2005.06.004

Martinez VD, Vucic EA, Becker-Santos DD, Gil L, Lam WL (2011) Arsenic exposure and the induction of human cancers. J Toxicol 2011:1-13. doi:10.1155/2011/431287

Mastrangelo G, Fadda E, Marzia V (1996) Polycyclic aromatic hydrocarbons and cancer in man. Environ Health Perspect 104(11):1166-1170
Michels KB (2005) The role of nutrition in cancer development and prevention. Int J Cancer 114(2):163-165. doi:10.1002/ijc.20662

Mierke CT (2013) Physical break-down of the classical view on cancer cell invasion and metastasis. Eur $\mathrm{J}$ Cell Biol 92(3):89-104. doi:10.1016/j.ejcb.2012.12.002

Mishra A, Liu S, Sams GH, Curphey DP, Santhanam R, Rush LJ, Schaefer D, Caligiuri MA (2012) Aberrant overexpression of IL15 initiates large granular lymphocyte leukemia through chromosomal instability and DNA hypermethylation. Cancer Cell 22(5):645-655. doi:10.1016/j.ccr.2012.09.009

Moore MM, Chen T (2006) Mutagenicity of bromate: implications for cancer risk assessment. Toxicology 221(2-3):190-196. doi:10. 1016/j.tox.2005.12.018

Murthy SS, Testa JR (1999) Asbestos, chromosomal deletions, and tumor suppressor gene alterations in human malignant mesothelioma. J Cell Physiol 180:150-157

NCI and NIEHS (2003) Cancer and the Environment. NIH publication no 03-2039. Retrieved from http://www.niehs.nih.gov/ health/materials/cancer_and_the_environment_508.pdf

O'Reilly KM, Mclaughlin AM, Beckett WS, Sime PJ (2007) Asbestosrelated lung disease. Am Fam Physician 75(5):683-688. Retrieved from http://www.ncbi.nlm.nih.gov/pubmed/17375514

Peltomäki P (2001) DNA mismatch repair and cancer. Mutat Res 488(1):77-85. doi:10.1016/S1383-5742(00)00058-2

Pepper JW, Scott Findlay C, Kassen R, Spencer SL, Maley CC (2009) SYNTHESIS: cancer research meets evolutionary biology. Evolut Appl 2(1):62-70. doi:10.1111/j.1752-4571.2008.00063.x

Podlaha O, Riester M, De S, Michor F (2012) Evolution of the cancer genome. Trends Genet TIG 28(4):155-163. doi:10.1016/j.tig. 2012.01.003

Poschl G, Seitz HK (2004) Alcohol and cancer. Alcohol Alcohol 39(3): 155-165. doi:10.1093/alcalc/agh057

Povey AC (2000) DNA adducts: endogenous and induced. Toxicol Pathol 28(3):405-414. doi:10.1177/019262330002800308

Rana SVS (2008) Metals and apoptosis: recent developments. J Trace Elem Med Biol 22(4):262-284. doi:10.1016/j.jtemb.2008.08.002

Ranson T, Vosshenrich CAJ, Corcuff E, Richard O, Müller W, Di Santo JP (2003) IL-15 is an essential mediator of peripheral NKcell homeostasis. Blood 101(12):4887-4893. doi:10.1182/blood2002-11-3392

Shen S, Lee J, Weinfeld M, Le XC (2008) Attenuation of DNA damage-induced p53 expression by arsenic: a possible mechanism for arsenic co-carcinogenesis. Mol Carcinog 47(7):508-518. doi: $10.1002 / \mathrm{mc} .20406$

Singh A, Prasad SM (2014) Remediation of heavy metal contaminated ecosystem: an overview on technology advancement. Int $\mathbf{J}$ Environ Sci Technol 12:353-366. doi:10.1007/s13762-0140542-y

Spencer SL, Gerety RA, Pienta KJ, Forrest S (2006) Modeling somatic evolution in tumorigenesis. PLoS Comput Biol 2(8):e108. doi:10.1371/journal.pcbi.0020108

Stickney JA, Sager SL, Clarkson JR, Smith LA, Locey BJ, Bock MJ, Hartung R, Olp SF (2003) An updated evaluation of the carcinogenic potential of 1,4-dioxane. Regul Toxicol Pharmacol 38(2):183-195. doi:10.1016/S0273-2300(03)00090-4

Sui X, Chen R, Wang Z, Huang Z, Kong N, Zhang M, Pan H (2013) Autophagy and chemotherapy resistance: a promising therapeutic target for cancer treatment. Cell Death Dis 4:e838. doi:10. 1038/cddis.2013.350

Trouiller B, Reliene R, Westbrook A, Solaimani P, Schiestl RH (2009) Titanium dioxide nanoparticles induce DNA damage and genetic instability in vivo in mice. Cancer Res 69(22): 8784-8789. doi:10.1158/0008-5472.CAN-09-2496

Tsai H-C, Baylin SB (2011) Cancer epigenetics: linking basic biology to clinical medicine. Cell Res 21(3):502-517. doi:10.1038/cr. 2011.24 
Uttara B, Singh AV, Zamboni P, Mahajan RT (2009) Oxidative stress and neurodegenerative diseases: a review of upstream and downstream antioxidant therapeutic options. Curr Neuropharmacol 7(1):65-74. doi:10.2174/157015909787602823

Vincent TL, Gatenby RA (2008) An evolutionary model for initiation, promotion, and progression in carcinogenesis. Int $\mathrm{J}$ Oncol 32(4):729-737. Retrieved from http://www.ncbi.nlm.nih.gov/ pubmed/18360700

Wallace AE, Gibson DA, Saunders PTK, Jabbour HN (2010) Inflammatory events in endometrial adenocarcinoma. J Endocrinol 206(2):141-157. doi:10.1677/JOE-10-0072

Wilkinson CF, Lamb IV JC (1999) The potential health effects of Phthalate Esters in Children's toys: a review and risk assessment. Regul Toxicol Pharmacol 30:140-155

Wogan GN, Hecht SS, Felton JS, Conney AH, Loeb LA (2004) Environmental and chemical carcinogenesis. Semin Cancer Biol 14(6):473-486. doi:10.1016/j.semcancer.2004.06.010
Yamasaki H, Mesnil M, Nakazawa H (1992) Interaction and distinction of genotoxic and non-genotoxic events in carcinogenesis. Toxicol Lett 64:597-604

Yu MW, Lien JP, Chiu YH, Santella RM, Liaw YF, Chen CJ (1997) Effect of aflatoxin metabolism and DNA adduct formation on hepatocellular carcinoma among chronic hepatitis B carriers in Taiwan. J Hepatol 27(2):320-330. Retrieved from http://www. ncbi.nlm.nih.gov/pubmed/9288607

Zavros Y, Eaton KA, Kang W, Rathinavelu S, Katukuri V, Kao JY, Samuelson LC, Merchant JL (2005) Chronic gastritis in the hypochlorhydric gastrin-deficient mouse progresses to adenocarcinoma. Oncogene 24(14):2354-2366. doi:10.1038/sj.onc. 1208407

Zhang L, Wang Y, Shang N, Smith MT (1998) Benzene metabolites induce the loss and long arm deletion of chromosomes 5 and 7 in human lymphocytes. Leuk Res 22(2):105-113 